\title{
Plasma lactate as a predictor of early childhood neurodevelopmental outcome of neonates with severe hypoxaemia requiring extracorporeal membrane oxygenation
}

\author{
Po-Yin Cheung, Charlene M T Robertson, N N Finer
}

\begin{abstract}
Although plasma lactate concentration has been widely used as an indicator of tissue hypoxia, no clinical study has been conducted to relate these values to the neurological outcome of sick neonates. Seventeen consecutively cared for and surviving neonates with severe hypoxaemia requiring extracorporeal membrane oxygenation (ECMO) were evaluated at a mean age of 19.6 months. The serial plasma lactate concentrations were significantly correlated with the scores of the Bayley Scales of Infant Development. Admission and peak plasma lactate of $\leqslant 15 \mathrm{mmol} / \mathrm{h}$ predicted favourable outcome (MDI and PDI $>70$ and no disability): sensitivity $100 \%$, specificity $88 \%$, positive predictive value $90 \%$, and negative predictive value $100 \%$.
\end{abstract}

Plasma lactate values could help predict neurodevelopmental outcome in these sick neonates.

(Arch Dis Child 1996; 74: F47-F50)

Keywords: lactate, prediction, hypoxaemia, ECMO

Severe hypoxaemia in neonates is associated with high mortality and morbidity. Extracorporeal membrane oxygenation (ECMO) has been successfully used as rescue treatment for these newborns with survival rates of about $80 \%$ from an international experience of more than 9000 neonatal ECMO cases reported. ${ }^{1}$ There is limited information available on different risk factors that best predict the outcome of infants receiving ECMO ${ }^{2-4}$

Hyperlactataemia is caused by increased production and defective utilisation as both pathways of lactate metabolism are oxygen dependent. ${ }^{5}$ Therefore, lactate has been used as an indicator of tissue hypoxia. An association with organ damage in hyperlactataemia is supported by animal hypoxic models, ${ }^{67}$ which suggest that plasma lactate values above 15 $\mathrm{mmol} / \mathrm{l}$ are associated with cerebral damage and concentrations of $25 \mathrm{mmol} / \mathrm{l}$ or greater are associated with tissue destruction, cerebral oedema, and death. Despite extensive clinical studies in critically ill adults correlating hyperlactataemia with survival, ${ }^{8}$ there have been limited clinical studies to address this issue in relation to neurological outcome both in adults and children.

In view of the universal hypoxic ischaemia seen in neonates requiring ECMO, serial plasma lactate values are measured in our unit as part of our routine management of these patients, to indicate tissue hypoxia. We have previously reported very high plasma lactate concentrations in infants requiring ECMO, and their association with high mortality. ${ }^{9}$ In this study we report the predictive value of plasma lactate and other clinical and biochemical measurements in relation to the neurodevelopmental outcome of infants surviving ECMO.

\section{Methods}

From July 1992 to December 1993, 29 infants (birthweights $\geqslant 2000 \mathrm{~g}$ and gestational ages $\geqslant 35$ weeks) with severe hypoxaemia requiring ECMO, were consecutively admitted into the neonatal intensive care unit (NICU) at Royal Alexandra Hospital. The ECMO programme at the Royal Alexandra Hospital was the first of its kind in Canada and currently the only one to service the western half of the country. This programme services the four western provinces of Manitoba, Saskatchewan, Alberta, and British Columbia. There are 120000 deliveries a year in the region. To our knowledge, since the start of the programme, only one infant has been referred for ECMO to the United States because of the unavailability of beds. Twenty four babies were transferred to the ECMO centre from other level III NICUs, one died before cannulation. To our knowledge, during that period of time, there were no other deaths of infants who were considered candidates and potential referrals to the ECMO programme. Excluding one unrelated surgical death, seven infants $(25 \%)$ died during the acute illness (six multiple organ failure and one severe intracranial haemorrhage); four (14\%) died before 6 months of age (two died after repair of congenital heart disorder, one after withdrawal of treatment because of severe periventricular leucomalacia found two weeks after successful decannulation, one infant with congenital diaphragmatic hernia died four months later secondary to pneumonia). Seventeen children $(61 \%)$ survived to be assessed at a mean age of 19.6 months; 16 at 17 to 30 months, and one at 10 months of age.

The protocol of management has been outlined before. ${ }^{9}$ Serial plasma lactate values were studied on admission and every 12 hours thereafter as part of the clinical management for infants referred or considered potential 
Table 1 Demographic characteristics and clinical and biochemical measurements of 17 ECMO survivors (mean (SD) [range], ${ }^{\star}$ median)

\begin{tabular}{lc}
\hline Male:female & $12: 5$ \\
Gestational age (weeks) & $40 \cdot 5(1 \cdot 66)[36-42]$ \\
Birthweight (g) & $3403(588 \cdot 1)[2120-4040]$ \\
Apgar scores at $1,^{\star} 5$ minutes & $5[0-9], 6[2-9]$ \\
Age at admission (hours) & $23 \cdot 1(24 \cdot 65)[0 \cdot 5-96]$ \\
Age ECMO started (hours) & $51 \cdot 1(48 \cdot 71)[15-214]$ \\
Duration of ECMO (hours) & $89 \cdot 1(33 \cdot 30)[38-139]$ \\
Venoarterial:venovenous ECMO & $7: 10$ \\
Duration of hospital stay (days) & $20 \cdot 2(11 \cdot 49)[8-53]$
\end{tabular}

ECMO candidates. These values were also studied every 12 hours after starting ECMO. Peak lactate concentration was the highest level recorded either before ECMO or within the first 12 hours of initiating ECMO, except for one child with septicaemia who had peak lactate 24 hours after starting ECMO. Our lack of experience in interpreting lactate values in critically ill neonates meant that we did not use the lactate values as criteria for decision making before or during ECMO.

Multidisciplinary assessments of the ECMO survivors at the tertiary NICU neonatal follow up clinics have been described before. ${ }^{10}$ Mental Developmental Index (MDI) and Psychomotor Developmental Index (PDI) were determined by the administration of the Bayley Scales of Infant Development (BSID-II) ${ }^{11}$ by reliability tested psychologists or psychometricians (under the direction of a chartered psychologist). Hearing was assessed by certified clinical audiologists. Apart from knowing that the infants had received ECMO, the assessors were unaware of the clinical state and the laboratory results of the patients. Hospital records and databases of neonatal follow up clinics were reviewed.

In this study, abnormal score in either MDI or PDI was defined as a standard score of $>2 \mathrm{SD}$ below the mean of normative data

Table 2 Clinical and biochemical measurements in nine normal ECMO survivors and eight disabled or delayed ECMO survivors (mean (SD), * median (range))

\begin{tabular}{|c|c|c|c|}
\hline & Normal $(n=9)$ & Disabled/delayed $(n=8)^{\star}$ & Pvalue \\
\hline $\begin{array}{l}\text { Before ECMO } \\
\mathrm{MAP}(\mathrm{mm} \mathrm{Hg}) \\
\mathrm{PaO}_{2}(\mathrm{kPa})^{\star} \\
\mathrm{PaCO}_{2}(\mathrm{kPa}) \\
\mathrm{Paw}\left(\mathrm{cm} \mathrm{H}_{2} \mathrm{O}\right)^{\star} \\
\text { Oxygenation index } \\
\mathrm{pH} \\
\text { Bicarbonate }(\mathrm{mmol} / \mathrm{h}) \\
\text { Dopamine }(\mu \mathrm{g} / \mathrm{kg} / \mathrm{min}) \\
\text { Epinephrine }(\mu \mathrm{g} / \mathrm{kg} / \mathrm{min})\end{array}$ & $\begin{array}{c}64(12 \cdot 6) \\
4 \cdot 8(2 \cdot 9-5 \cdot 7) \\
5 \cdot 5(4 \cdot 51) \\
20(18-21) \\
54(47-86) \\
7 \cdot 48(0 \cdot 171) \\
25(6 \cdot 2) \\
17(4 \cdot 4) \\
0 \cdot 8(0 \cdot 57)\end{array}$ & $\begin{array}{c}59(9 \cdot 3) \\
4 \cdot 8(2 \cdot 0-7 \cdot 2) \\
6 \cdot 4(3 \cdot 17) \\
19(14-23) \\
55(45-140) \\
7 \cdot 37(0 \cdot 248) \\
24(7 \cdot 5) \\
22(7 \cdot 1) \\
1 \cdot 1(0 \cdot 66)\end{array}$ & $\begin{array}{l}\text { NS } \\
\text { NS } \\
\text { NS } \\
\text { NS } \\
\text { NS } \\
\text { NS } \\
\text { NS } \\
\text { NS } \\
\text { NS }\end{array}$ \\
\hline $\begin{array}{l}\text { Admission lactate }(\mathrm{mmol} / \mathrm{l}) \\
\text { Peak lactate }(\mathrm{mmol} / \mathrm{l}) \\
12 \text { hour lactate }(\mathrm{mmol} / \mathrm{l})\end{array}$ & $\begin{array}{r}7 \cdot 1(2 \cdot 67) \\
10 \cdot 2(2 \cdot 41) \\
6 \cdot 3(3 \cdot 03)\end{array}$ & $\begin{array}{l}16 \cdot 1(5 \cdot 93) \\
20 \cdot 2(5 \cdot 27) \\
11 \cdot 4(4 \cdot 71)\end{array}$ & $\begin{array}{l}0.001 \\
0 \cdot 0001 \\
0.017\end{array}$ \\
\hline
\end{tabular}

${ }^{\star}$ Disabled, see text for definition; delayed $=$ Bayley's scores $<70$.

$\mathrm{MAP}=$ mean arterial pressure; $\mathrm{Paw}=$ mean airway pressure; oxygenation index $=\mathrm{Paw}(\mathrm{cm}$

$\mathrm{MAP}=$ mean arterial pressure; $\mathrm{Paw}=$ mean airway pressure; oxygenation ind
$\left.\mathrm{H}_{2} \mathrm{O}\right) \times$ inspired oxygen concentration $\div \mathrm{PaO}_{2}(\mathrm{~mm} \mathrm{Hg} \times 100) ; \mathrm{NS}=\mathrm{P}>0.05$ (mean 100; SD 15). Neurodevelopmental disability was defined as a child with one or more of the following diagnoses:

(i) cerebral palsy of all types or severity;

(ii) legal blindness (corrected visual acuity of the better eye $<20 / 200$ );

(iii) hearing loss (neurosensory hearing loss of $>30 \mathrm{~dB}$ in the better ear);

(iv) cognitive delay (MDI of $>3 \mathrm{SD}$ below mean on standardised testing).

Two or more diagnosed disabilities rendered the child multiply disabled.

\section{STATISTICAL ANALYSIS}

Student's $t$ and Rank sum tests were used to study the differences between the groups. Pearson's product moment test and Fisher's exact test were used to study the correlation between continuous and categoric variables, respectively. Best subsets regression was performed to analyse the variance of clinical and biochemical measurements (with $P$ values $<0.1$ by Pearson's product moment test) in the prediction of the MDI and PDI of BSID-II. A $P$ value of $<0.05$ was considered significant.

\section{Results}

The plasma lactate concentrations, clinical and biochemical measurements of the seven acute illness related deaths have been reported before. ${ }^{9}$ Three of the four late deaths (two postrepair surgical deaths and one pneumonia) had serial plasma lactate concentrations of $<15 \mathrm{mmol} / \mathrm{l}$. One infant with admission and peak plasma lactate values of 16 and $20 \mathrm{mmol} / \mathrm{l}$, respectively, developed severe periventricular leucomalacia.

The demographic, clinical, and biochemical characteristics of the remaining 17 survivors are shown in tables 1 and 2 . The neurodevelopmental outcome of six disabled children and their serial plasma lactate values are described in table 3. Three infants had severe intraventricular haemorrhage with parenchymal extension documented by brain computed tomography scan in addition to the abnormal neurological findings. Almost all normal survivors had normal computed tomograms; one infant had a small intraventricular haemorrhage.

Of the six children (35\%) with MDI or PDI $<70$, four were disabled (table 3 ). The remaining two infants had congenital diaphragmatic hernia repaired. The two children with isolated neurosensory hearing loss had normal scores. The MDI and PDI were significantly

Table 3 Plasma lactate (mmoll) in relation to neurodevelopmental outcome in six disabled children

\begin{tabular}{|c|c|c|c|c|c|c|}
\hline $\begin{array}{l}\text { Case } \\
\text { No }\end{array}$ & Diagnosis & $\begin{array}{l}\text { Admission } \\
\text { lactate }\end{array}$ & $\begin{array}{l}\text { Peak } \\
\text { lactate }\end{array}$ & $M D I$ & $P D I$ & Disabilities \\
\hline $\begin{array}{l}1 \\
2 \\
3^{\star} \\
4^{\star} \\
5^{\star} \\
6\end{array}$ & $\begin{array}{l}\text { CDH } \\
\text { CDH } \\
\text { MAS } \\
\text { GBS } \\
\text { MAS } \\
\text { CDH }\end{array}$ & $\begin{array}{r}10 \cdot 5 \\
3 \cdot 7 \\
21 \cdot 4 \\
18 \cdot 6 \\
15 \cdot 2 \\
23 \cdot 2\end{array}$ & $\begin{array}{l}15 \cdot 0 \\
24 \cdot 8 \\
21 \cdot 4 \\
18 \cdot 6 \\
15 \cdot 2 \\
30 \cdot 1\end{array}$ & $\begin{array}{r}84 \\
85 \\
<50 \\
<50 \\
70 \\
60\end{array}$ & $\begin{array}{r}87 \\
95 \\
<50 \\
<50 \\
63 \\
<50\end{array}$ & $\begin{array}{l}\text { Moderate high frequency neurosensory hearing loss } \\
\text { Severe to profound neurosensory hearing loss } \\
\text { Dependently disabled, legal blindness (optic atrophy), spastic quadriplegic CP } \\
\text { Dependently disabled, hydrocephalus with shunt, spastic quadriplegic CP } \\
\text { Spastic quadriplegic CP } \\
\text { Spastic quadriplegic CP, visual impairment }\end{array}$ \\
\hline
\end{tabular}

^Severe intraventricular haemorrhage with parenchymal extension.

MDI=Mental Developmental Index; PDI = Psychomotor Development Index; $\mathrm{CDH}=$ congenital diaphragmatic hernia;

MAS=meconium aspiration syndrome; $\mathrm{GBS}=$ group Streptococcal septicaemia; $\mathrm{CP}=$ cerebral palsy . 


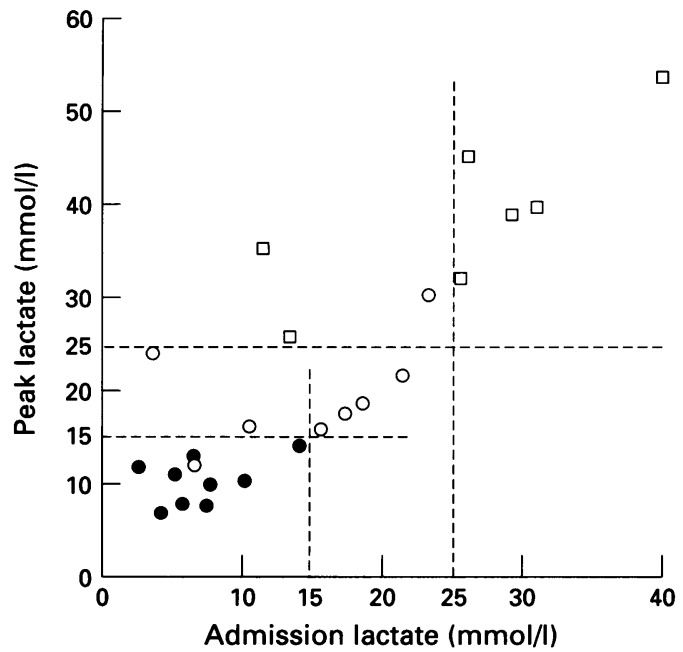

Admission and peak plasma lactate values of 24 neonates requiring ECMO in relation to the outcome (seven early deaths $\square$, eight with $M D I$ or $P D I<70$ and/or disability $\bigcirc$, nine normal survivors $\mathrm{O}$ ).

correlated ( $r=0 \cdot 79, P<0 \cdot 001)$. Regarding the association between primary diagnoses and neurodevelopmental outcome, congenital diaphragmatic hernia was associated with neurodevelopmental disability or abnormal MDI or PDI of borderline significance $(P=0 \cdot 05)$. No significant relations were found between neurodevelopmental morbidity and type of ECMO (venoarterial vs venovenous), neonatal seizures, neonatal brain tomography scan results, and respiratory status on follow up.

No significant correlations were found between the scores of BSID-II and other clinical and biochemical measurements, but the plasma lactate values, on admission, at peak, and 12 hours after starting ECMO were significantly correlated with MDI $(r=-0.79$ $(\mathrm{P}<0.001), \quad r=-0.58 \quad(P=0.01), \quad r=-0.71$ $(P=0.001)$, respectively); and PDI $(r=-0.75$ $(P<0.001), \quad r=-0.58 \quad(P=0.01), \quad r=-0.62$ $(P<0.01)$, respectively) $(\beta \leqslant 0 \cdot 1)$. There were no significant correlations between plasma lactate values and $\mathrm{PaO}_{2}, \mathrm{OI}, \mathrm{pH}$ and serum bicarbonate concentrations. The serial plasma lactate concentrations of disabled or delayed survivors were also significantly higher than those of normal neurodevelopment (table 2).

Using best subsets regression to analyse the following variables - serial plasma lactate and admission $\mathrm{PaO}_{2}$ - the values of $\mathrm{MDI}$ and PDI could be best predicted with plasma lactate values, on admission and 12 hours after starting ECMO (adjusted $r^{2}=0.70$ and 0.58 , respectively). The $\mathrm{PaO}_{2}$ on admission significantly improved the prediction of MDI but not PDI (adjusted $r^{2}$ to 0.78 and $P=0.03$, adjusted $r^{2}$ to 0.61 and $P=0 \cdot 19$, respectively).

Using an admission plasma lactate value of $\leqslant 15 \mathrm{mmol} / \mathrm{l}$ to predict favourable neurodevelopmental outcome (MDI and PDI $\geqslant 70$ and no disability, prevalence $53 \%$ ), the sensitivity and specificity were $100 \%$ and $63 \%$, with positive and negative predictive values of $75 \%$ and $100 \%$, respectively. The addition of peak plasma lactate $\leqslant 15 \mathrm{mmol} / 1$ improved the specificity to $88 \%$ and positive predictive value to $90 \%$ (figure). Admission $\mathrm{pH} \geqslant 7.15$ predicted favourable outcome with sensitivity $91 \%$, specificity $33 \%$, positive and negative predictive values of $71 \%$ and $66 \%$, respectively. Admission serum bicarbonate concentration $\geqslant 15 \mathrm{mmol} / \mathrm{l}$ predicted favourable outcome with sensitivity $91 \%$, specificity $17 \%$, positive and negative predictive values of $67 \%$ and $50 \%$, respectively. Both the admission and peak plasma lactate values $\leqslant 15 \mathrm{mmol} / 1$ were associated with favourable neurodevelopmental outcome $(P<0 \cdot 005)$. Neither $\mathrm{pH}$ nor serum bicarbonate were significantly related to outcome.

\section{Discussion}

This is the first study on the predictive value and the association of hyperlactataemia with neurodevelopmental morbidity in critically ill infants. There are few clinical data for sick neonates which show an association between hyperlactataemia and mortality, despite extensive studies in critically ill adults. We have previously shown that high lactate values are associated with a high mortality. ${ }^{9}$ Using admission and peak plasma lactate values of 15 $\mathrm{mmol} / \mathrm{l}$, the outcome of early death and neurodevelopmental disability could be predicted with a sensitivity of $93 \%$, specificity of $100 \%$, and positive and negative predictive values of $100 \%$ and $90 \%$, respectively.

APACHE II, PRISM II, CRIB and other scoring systems based on a combination of clinical and laboratory measurements have been developed to predict outcome in critically ill adults, children, and newborns respectively. ${ }^{12-14}$ While no score has been validated for the prediction of long term outcome in sick neonates, plasma lactate values may provide a way of comparing severity of illness and of prognosticating outcome, in addition to the quantification of tissue hypoxia.

This study provides follow up information on the occurrence of neurodevelopmental sequelae in a small group of extremely ill near term newborns. Our study complements the findings of various follow up studies on the neurological outcome of ECMO survivors, showing no association between outcome and demographic data, physiological indicators of severity of illness, or duration of ECMO. ${ }^{2-4}$ The association between congenital diaphragmatic hernia and adverse neurodevelopment is consistent with other reports. ${ }^{15}$

Plasma lactate values could be a useful tool in the prognosis of outcome. Other available clinical and biochemical measurements did not seem to be useful. Further prospective studies are required to evaluate the predictive value of hyperlactataemia in these critically ill neonates.

We thank Drs T K Belgaumkar, R S Sauve, and M F Whitfield, directors of the Neonatal Follow up Clinics of Regina, Saskatchewan; Calgary, Alberta; and Vancouver, British Columbia for their contribution of follow up information.

This follow up protocol had been approved by the Ethics Committee, Glenrose Rehabilitation Hospital

The information in this paper has been published in part as an abstract (Ped Res 1994; 35: A1300) and presented in part at the Xth Annual CNMC ECMO Symposium, Colorado, 1994. 
1 Neonatal ECMO Registry. Extracorporeal Life Support Organization (ELSO). Michigan: Ann Arbor, 1994

2 Glass P, Miller M, Short B. Morbidity for survivors of extracorporeal membrane oxygenation: neurodevelopmenta outcome at 1 year of age. Pediatrics 1989; 83: 72-8.

3 Hofkosh D, Thompson AE, Nozza RJ, Kemp SS, Bowen A Feldman HM. Ten years of extracorporeal membrane oxygenation: neurodevelopmental outcome. Pediatrics 1991; 87: 549-55.

4 Flusser H, Dodge NN, Engle WE, Garg BP, West KW. Neurodevelopmental outcome and respiratory morbidity Giratory morbidity year of age. $¥$ Perinatol 1993; 13: 266-71.

5 Mizock BA, Falk JL. Lactic acidosis in critical illness. Crit Care Med 1992; 20: 80-93.

6 Mujsce DJ, Lowfighit J, Vannucci RC. Physiologic and neuropathologic aspects of hypothermic circulatory arrest in newborn dogs. Ped Res 1990; 28: 354-60.

7 Myers RE, Yamaguchi M. Comparison of brain biochemical changes produced by anoxia and hypoxia. $f$ Neuropathol Exp Neurol 1976; 32: 302.

8 Vincent JL, Dufaye P, Berre J, Leeman M, Degaute JP, Kahn RJ. Serial lactate determinations during circulatory shock. Crit Care Med 1983; 11: 449-51.
9 Cheung P-Y, Finer NN. Plasma lactate concentration as a predictor of mortality in neonates with severe hypoxaemia requiring extracorporeal membrane oxygenation. f Pediat 1994; 125: 763-8

10 Robertson CMT, Finer NN, Sauve RS, et al. Neurodevelopmental outcome after neonatal extracorporeal membrane oxygenation. Can Med Assoc $\mathcal{F}$ 1995; 152 1981-8.

11 Bayley N. Bayley scales of infant development manual. 2nd Edn. San Antonio, Texas: The Psychological Corporation/Harcourt Brace \& Co, 1993.

12 Knaus WA, Draper EA, Wagner DP, Zimmerman JE. APACHE II: a severity of disease classification system. Crit Care Med 1985; 13: 818-29.

13 Pollack MM, Patel KM, Ruttimann UE. PRISM III. Ped Res 1995; 37: A296.

14 The International Neonatal Network. The CRIB (clinical risk index for babies) score: a tool for assessing initial neonatal risk and comparing performance of neonatal intensive care units. Lancet 1993; 342: 193-8.

15 Lund DP, Mitchell J, Kharasch V, et al. Congenital diaphragmatic hernia: the hidden morbidity. $\mathcal{F}$ Pediatr Surg 1994; 29: 258-64. 